\title{
Ondina: sobre as relações entre verdade, ima- gem e natureza
}

\author{
Carlos Eduardo Félix da Costa ${ }^{1}$, Daniel B. Portugal ${ }^{2}$ e Rafaela Travassos Sarinho ${ }^{3}$
}

Resumo: Este trabalho explora a obra Ondina (2005), do artista visual Walmor Corrêa. Partindo de uma perspectiva arqueológica, tal como o termo é definido por Foucault, seu objetivo é investigar como a obra mencionada se relaciona com a episteme atual ao representar, a partir de componentes típicos do universo científico, seres do imaginário popular.

Palavras-chave: Episteme, Ciência, Mundo Natural, Ondina.

\section{Ondine: On the relationship among Truth, Image and Nature}

\begin{abstract}
This research analyzes the work Ondina (2005), by visual artist Walmor Corrêa. Starting from an archaeological perspective, as the term defined by Foucault, it aims to investigate how the work relates to the current episteme by representing, from typical components of the scientific universe, figures of the popular imagination.
\end{abstract}

Keywords: Episteme; Science; Natural World; Ondine.

1 Artista plástico e professor do Departamento de Artes e Design da PUC-Rio, onde coordena o LINDA - Laboratório Interdisciplinar em Natureza, Design e Arte. Vínculo institucional: PUC-Rio, Rua Marquês de São Vicente, 225, Gávea - Rio de Janeiro, RJ. E-mail: cadu@puc-rio.br. ORCID: https://orcid.org/0000-0002-4148-4430. Lattes iD: http://lattes.cnpq.br/0757744155897986. Rio de Janeiro, Brasil.

2 Professor do Programa de Pós-Graduação em Design da ESDI/UERJ, onde coordena o DEMO - Laboratório de Design, epistemologia e moralidade. Vínculo institucional: ESDI/UERJ, Rua do Passeio, 80, Lapa - Rio de Janeiro, RJ. E-mail: dportugal@ esdi.uerj.br. ORCID: https://orcid.org/0000-0002-2903-1893. Lattes iD: http://lattes.cnpq.br/0196363528063237. Rio de Janeiro, Brasil.

3 Doutoranda em Design (PUC-Rio). Mestre (PUC-Rio). Graduada em Design (UFPE). Membro e pesquisadora do Laboratório Interdisciplinar em Natureza, Design e Artes (LINDA, PUC-Rio). Vínculo institucional: PUC-Rio, Rua Marquês de São Vicente, 225, Gávea - Rio de Janeiro, RJ. E-mail: rafasarinho@gmail.com. ORCID: https://orcid.org/0000-0003-4703-6505. Lattes iD: http:// lattes.cnpq.br/7312388728535860. Rio de Janeiro, Brasil. 


\section{Os sentidos da natureza: ciência, mito e verdade}

Por muitos séculos, as criaturas selvagens foram elemento central do imaginário popular - protagonistas de muitas lendas e fábulas. As histórias sobre esses seres - aprendidas comunitariamente, ensinadas de pai para filho - revelavam a existência de um mundo repleto de significados, de sinais emitidos pela natureza. O mundo organizado dessa forma suscitava a visão da natureza como um sistema simbólico à espera de deciframento. Nos bestiários medievais, por exemplo, o reino animal estava repleto de tipos e símbolos que refletiam significados aos homens. Conforme mostra Thomas (2010), a mosca era um lembrete da brevidade da vida e o vaga-lume, da luz do Espírito Santo. Certos animais eram, muitas vezes, elevados a condições especiais quando comparados a outras espécies: as lebres, corujas e corvos, por exemplo, reuniam histórias que remetiam a uma existência quase divina.

No final da Idade Média, um dos principais representantes dessa visão de mundo foi Paracelso, homem típico de uma época de transição que mesclava o animismo - a natureza, na sua visão, ainda era povoada por bruxas, íncubos, súcubos, diabos, sílfides e ondinas - ao empirismo científico, calcado na experimentação de mistura de plantas e na formulação de sua ciência natural. Considerado por J11ung como o "pai das ciências naturais", Paracelso interpretou a natureza como um sistema vivo, em correspondência com o mundo: "para cada ens morbi correponde um arcanum da natureza" (JUNG, 2011 , p. 8). Seu mundo é formado, em pequena e em grande escala, de partículas vivas. "O saber não está armazenado em um só lugar, mas disperso por toda a superfície da terra” (PARACELSO, 1973, p. 15). Na base de seu pensamento está a visão do homem como um microcosmo, dentro de uma grande ordem superior, o macrocosmo. A vida humana significa, dessa forma, uma vida relacionada à natureza. Trata-se de uma visão emblemática de mundo, na qual este é formado por símbolos que conectam o mundo natural a um sistema de linguagens metafóricas.

Segundo Foucault (2007), o mundo natural convivia então - na idade préclássica - plenamente com a magia natural. A partir de uma episteme que acolhia magia e erudição, configuraram-se saberes que entendiam a natureza como um vasto espaço a se interpretar a partir de jogos de semelhança entre objetos naturais e lendas, narrativas, experiências etc.

1 Ver, por exemplo, os bestiários disponibilizados pelo projeto The Aberdeen Bestiary, da Universidade de Aberdeen. Disponível em: https://www.abdn.ac.uk/bestiary. Acesso em: 20 jun. 2020. 
Nós, homens, descobrimos tudo o que está oculto nas montanhas por meio de sinais e correspondências exteriores; e é assim que encontramos todas as propriedades das ervas e tudo o que está nas pedras. Nada há nas profundezas dos mares, nada nas alturas do firmamento que o homem não seja capaz de descobrir. Não há montanha bastante vasta para ocultar ao olhar do homem o que nela existe; isso the é revelado por sinais correspondentes (PARACELSO apud FOUCAULT, 2007, p. 44-45).

Em oposição a essa tendência de enxergar símbolos em movimentos da natureza, foram surgindo, por volta dos séculos XVI e XVII, novas interpretações que, aos poucos, organizaram as narrativas tradicionais sobre novos pressupostos. Uma das fontes relevantes para tais interpretações emergentes foi a Reforma Protestante, na medida em que atacava as manifestações "encantadas" do mundo, promovendo a ideia de que a civilização humana começa com o afastamento, conquista e dominação da natureza. Segundo Thomas (2010), os protestantes mais radicais foram os que mais influenciaram este corte com a visão tradicional: sensíveis a qualquer vestígio aparente de paganismo, eram bastante hostis à ideia de que a flora e a fauna tivessem algum poder protetor e não demonstravam qualquer simpatia pela relação simbólica com o mundo natural.

Pensadores dessa época passaram a prestar mais atenção em características como a estrutura física dos animais e a organizar sistemas mais rígidos de classificação, procurando sistematizar a natureza. Ao mesmo tempo, caracterizavam os relatos populares como retrato de uma ignorância vulgar. Francis Bacon, um dos precursores da ciência moderna, escreveu que os antigos significados emblemáticos atribuídos às criaturas não eram inerentes a elas, mas apenas invenções do homem. Assim, o rompimento com a tradição alegórica foi dando espaço a um pensamento hostil acerca da relação entre o humano e a natureza.

É provavelmente de uma visão imperfeita deste peixe (a vaca-marinha) que a ideia das sereias, tritões e sirenas apareceu pela primeira vez. Esta criatura tem um modo de se erguer ereta e permanecer assim por alguns minutos, com meio corpo fora d'agua; uma pessoa que olhasse para ela à distância, diante dessa postura, veria alguma coisa como mãos e seios e talvez bastasse isso para dar origem aos relatos sobre sereias, etc (BACON apud THOMAS, 2010, p. 112).

A consolidação desse tipo de empirismo racionalista estimulou um menosprezo ao mundo natural, pois seu propósito era fazer dos homens senhores e possuidores da natureza - saber seria poder. Em seu Novum Organum, Bacon (1997, p. 11, [§ I]), afirma: "O homem, [...] intérprete da natureza, faz e entende tanto quanto constata, pela observação dos fatos [...], sobre a ordem da natureza; não sabe nem pode mais". Nos aforismos XVIII, XXIII e XXVI, Bacon critica o que chama de ídolos da mente, baseados na "ante- 
cipação da natureza (temerário e prematuro)" (Ibidem, p. 17), e defende uma interpretação calcada no "trato direto das coisas".

Resta-nos um único e simples método, para alcançar os nossos intentos: levar os homens aos próprios fatos particulares e às suas séries e ordens, a fim de que eles, por si mesmos, se sintam obrigados a renunciar às suas noções e comecem a habituar-se ao trato direto das coisas (IBIDEM, p. 19, [§ XXXVI]).

A reivindicação de um "trato direto das coisas", no sentido da observação empírica, factual, instaurou, ao mesmo tempo, um corte profundo entre o homem e a natureza - corte que limpou o terreno para o exercício ilimitado da dominação humana. Segundo Foucault (2007), o século XVII marca o início de um ordenamento que privilegia o humano, a quem caberia representar, classificar e trocar: o mundo natural foi aos poucos enquadrado em sistemas classificatórios, desencorajando qualquer narrativa que de alguma forma ameaçasse a nova divisão hierárquica e assimétrica estabelecida.

A ciência natural está, dessa forma, ligada à fixação de características "objetivas" ao mundo natural. Uma das práticas realizadas pelos naturalistas da época era a separação em partes - distinção e isolamento dos corpos das plantas e dos animais. Pela observação e categorização, eram estabelecidos critérios que pudessem ser aplicados de modo generalizado. Lineu - que teve grande influência no desenvolvimento da taxonomia botânica e animal nos séculos XVIII e XIX, como criador da nomenclatura binominal e da classificação científica - oferece as seguintes diretrizes para os naturalistas: "distingue pela vista as partes dos corpos naturais, descreve-as convenientemente segundo o número, a figura, a posição e a proporção e as nomeia" (LINEU apud FOUCAULT, 2007, p. 223).

Assim, foi sendo constituída, vagarosamente, uma linguagem universal a partir do agrupamento das existências naturais em sistemas de identidades e diferenças. Institui-se, dessa forma, um sistema que privilegia certas características em detrimento de outras. Sistema arbitrário, nas palavras de Foucault, visto que "negligencia, de maneira regulada, toda diferença e toda identidade que não recai sobre uma estrutura privilegiada" (Ibidem, 2007, p. 193). A estrutura desse sistema repousa em um novo suporte epistemológico: conhecer propriamente é ter diante de si a classificação ou a possibilidade de classificar. Sob uma forma concreta - conforme certos métodos -, a natureza se aloja inteira em uma taxonomia. Como consequência, são estabelecidos quadros que fundam o discurso científico: as espécies vivas inseridas em uma linguagem universal, ganham significados unívocos. 
O método, alma da ciência, designa à primeira vista qualquer corpo da natureza, de tal sorte que esse corpo enuncia o nome que lhe é próprio, e que esse nome evoca todos os conhecimentos que puderam ser adquiridos no curso do tempo acerca do corpo assim nomeado: de modo que na extrema confusão se descobre a ordem [...] (LINEU apud FOUCAULT, 2007, p. 221).

Em resumo: o mundo natural foi organizado, a partir da idade clássica, em uma gramática rígida, completamente diferente do mundo dinâmico de Paracelso, que mobilizava as palavras e as coisas em uma malha fluida e dinâmica. Porém, a que se deveria essa súbita transformação em como as coisas são percebidas, descritas, enunciadas? Um estudo arqueológico, nos moldes foucaultianos, compreende que todo conhecimento é provisório, definido, em cada época, por uma estrutura organizada - o que ele denomina episteme. A arqueologia pretende explorar as diferentes condições (filosóficas, técnicas, sociais, econômicas etc.) de uma época, e como elas se relacionam à emergência de certos saberes.

A fixação de certa episteme depende de todo um conjunto de práticas, incluindo a relação com os meios do conhecimento. No caso da virada epistêmica que nos interessa, particularmente, ganham relevância em como o saber é valorizado e distribuído: a imprensa, a edição, as bibliotecas, ambientes expositivos etc. Tais práticas corroboram com a perpetuação dos saberes científicos, deixando a impressão de que não há espaço para outros saberes. A arqueologia, na medida em que procura justamente entender como certos valores de verdade são articulados e validados, pode pautar estudos que se interessem por saberes que se distanciam dos valores de verdade científicos - e, portanto, também do "bom senso" cientificista.

Seguindo tal perspectiva, este trabalho questiona a universalidade dos significados, e pretende evidenciar um jogo de rarefação imposto em torno dos enunciados - ou seja, certa dinâmica que torna cada vez mais restrita a lista daquilo que pode ser dito com pretensão de legitimidade. Conforme afirma Berger (1999), a arte sempre foi uma forma privilegiada de articular e de exercitar novos regimes de compreensão do mundo. Com base nesse entendimento, e como exercício exploratório, este trabalho investiga alguns enunciados que colocam em questão a episteme que privilegia o homem como senhor do mundo natural. Partindo da leitura da série Unheimlich, imaginário popular brasileiro (2005), do artista visual Walmor Corrêa, pretende-se apresentar a arte como um campo particularmente frutífero para a experimentação de narrativas relegadas ao silêncio pelo cânone científico.

Unheimlich é uma série constituída por cinco pinturas de personagens do folclore brasileiro: Curupira, Ipupiara, Cachorra da Palmeira, Capelobo e Ondina. Atentando mais especificamente para a obra Ondina, analisa- 
remos a seguir como ela valoriza aspectos tradicionalmente rejeitados pela atitude científica, usando, para tal fim, o próprio universo visual da ciência. Ondina é um trabalho que resgata narrativas míticas e, a partir de uma hibridização retórica entre arte e ciência, especula com diferentes regimes de verdade.

\section{Uma leitura de Ondina: ciência como cenário ficcional}

Ondina atua na fronteira entre o real e o imaginário. Apresenta, a partir de desenhos de anatomia típicos dos livros científicos, partes dos órgãos que comporiam uma Ondina (mais detalhes sobre esse ente adiante). É importante pensar a aproximação que Corrêa faz entre o humano e a figura mítica a partir da organização de certos componentes visuais.

Figura 1

Walmor Corrêa Ondina, Unheimlich, Imaginário Popular Brasileiro, 2005 Acrílica e grafite sobre tela, $195 \mathrm{x}$ $130 \mathrm{~cm}$

Fonte: www.walmorcorrea.com.br/ obra/unheimlich-imaginario-popular-brasileiro

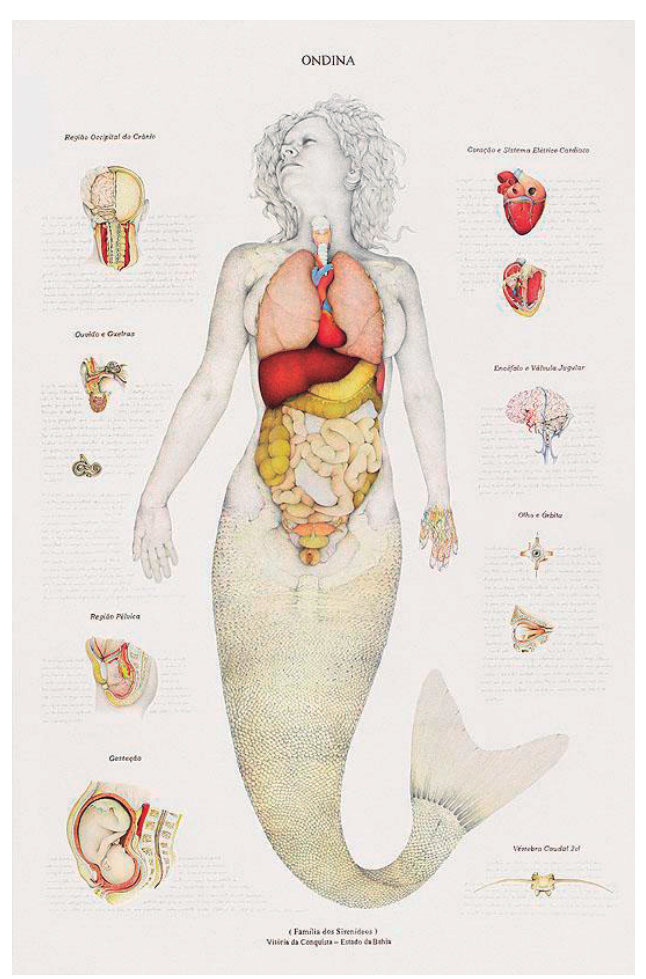

À primeira vista, seus desenhos, parecem ilustrações da história natural. No entanto, quando observamos as imagens pintadas, percebemos que não se trata exatamente de representações naturalistas de animais que povoam o cotidiano. $\mathrm{O}$ artista representa a taxidermia de uma fauna fantástica que provoca nossa percepção, principalmente porque se apresentam mais como possibilidades científicas do que como meras alucinações artísticas (CHIARELLI, 2002).

Segundo o artista, a série foi inspirada em uma carta escrita por Padre Anchieta em 1560 que assevera a existência de "espectros noturnos" em terras brasileiras. Na carta, o sacerdote narra suas primeiras impressões sobre certos demônios temidos pelos indígenas. 
Acrescentarei agora poucas palavras acêrca dos espectros noturnos ou antes demonios com que costumam os Indios aterrar-se. É cousa sabida e pela bôca de todos corre que ha certos demonios, a que os Brasis chamam corupira, que acometem aos Indios muitas vezes no mato, dão-lhes de açoites, machucam-os e matam-os. São testemunhas disto os nossos Irmãos, que viram algumas vezes os mortos por eles. [...] Ha tambem nos rios outros fantasmas, a que chamam Igpupiára, isto é, que moram n'agua, que matam do mesmo aos Indios. [...] Ha tambem outros, maximè nas praias, que vivem a maior parte do tempo junto do mar e dos rios, e são chamados baetatá, que quer dizer "cousa de fogo", o que é o mesmo como se dissesse "o que é todo fogo". Não se vê outra cousa senão facho cintilante correndo daqui para ali; acomete rapidamente os Indios e mata-os, como os curupiras: o que seja isto, ainda não se sabe com certeza. Há tambem outros espectros do mesmo modo pavorosos, que não só assaltam os Indios, como lhes causam dano; o que não admira, quando por êstes e outros meios semelhantes, que longo fôra enumerar, quer o demonio tornar-se formidavel a êstes Brasis, que não conhecem a Deus, e exercer contra eles tão cruel tirania (ANCHIETA, 1997, p. 34-35).

Uma das fontes relevantes da figura de Ondina é o Livro das ninfas, sílfides, pigmeus e salamandras e outros espíritos, de Paracelso. Para Agamben (2010), tal livro ilustra uma série de conexões entre o mundo "visível" e o "invisível". Com efeito, Paracelso (1996) descreve a existência de seres elementais - os quais também chama, posteriormente, de espíritos da natureza -, grupo que se subdivide em quatro distintos arquétipos: da terra, da água, do ar e do fogo. A diferença essencial entre os seres humanos e os elementais é que estes últimos careceriam de uma alma divina, enquanto os seres humanos seriam compostos por três partes: um corpo elementar, um espírito e uma alma divina mortal. As Ondinas (ou ninfas) são as principais representantes do arquétipo da água, sereias que despertam do elemento aquoso e partem em busca de uma alma humana. Para alcançar a mortalidade, devem conseguir uma alma, através do casamento com um humano.

Importante perceber que Paracelso não foi o único em sua época a contemplar e descrever a existência de seres "fantásticos" na natureza. Sua visão, apesar de constantemente refutada pela crescente percepção da natureza como algo a ser dominado - principalmente pelos precursores do Iluminismo -, era compartilhada por outros autores importantes da época que, assim como ele, deixaram registros de seus estudos e percepções sobre o mundo natural. É o caso de Ambroise Paré, médico francês, que produziu, entre outras publicações, o livro Des monstres et Prodiges (PARÉ, 1982), uma enciclopédia ilustrada de curiosidades sobre monstros e tipos de bestas, meio humana e meio animalescas. Tal como Paracelso, Paré (1982) reconhecia a presença desses seres selvagens como um fenômeno natural, e não como uma invenção ou uma ficção pagã. Ao listarem como habitantes do mundo os selvagens, ninfas e gnomos, Paracelso e Paré traçavam o caminho da episteme da época. 
Figura 2 Ambroise Paré Representação de tritão e sereia em Des monstres et Prodiges, s.d, 1573 Fonte: Bartra, 1994, p. 162

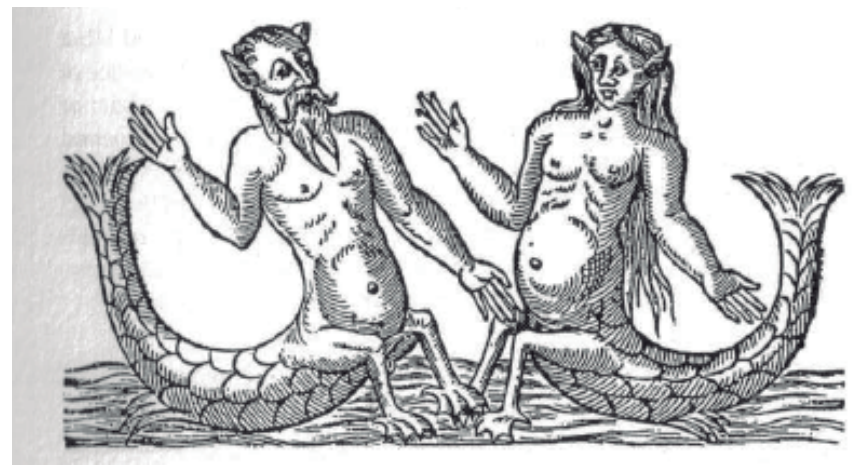

Muitas narrativas como as de Paracelso e Paré foram esquecidas e apagadas ao longo dos anos; e as que sobraram perderam legitimidade com a consolidação da História Natural. A ciência, como narrativa limitada, organizou um conjunto de categorias que "parece excluir, ou não considerar como válidas, outras formas de nomear, entender o mundo que não são aquelas que passam pelo enquadramento dos nomes" (SANTOS, 2000, p. 252).

Gonçalves (2011) mostra que a lida com essa categorização do mundo está intrinsecamente vinculada a uma separação entre ficção e realidade, verdade versus mentira. As categorias já carregam consigo não apenas certos valores de verdade, mas a própria possibilidade de ligação com outras categorias, que emprestam uma forma específica ao mundo, pois conformam o que pode ou não ser pensado ou imaginado em dado momento. Para evidenciar esse ponto, Foucault (2007) evoca, no prefácio de As palavras e as coisas, certa Enciclopédia chinesa concebida por Jorge Luís Borges. A Enciclopédia provoca uma leitura perturbadora, pois nos vemos confrontados com a impossibilidade de entender a classificação que ela propõe. Os animais, segundo ela, estariam divididos em: “[...] b) embalsamados, c) domesticados, d) leitões, e) sereias, f) fabulosos, g) cães em liberdade, $[\ldots]$, i) que se agitam como loucos [...]" (Ibidem, p.IX). Tal como a Enciclopédia chinesa, Ondina justapõe elementos estranhos (para nós, que olhamos de um lugar específico) e brinca, ao colocar o espectador em um lugar incômodo, uma vez que põe em questão as categorias lógicas com as quais ele pensa, observa e classifica. Contudo, no caso de Ondina, conseguimos vislumbrar por meio da obra, na aproximação entre atlas de anatomia e seres míticos, um novo lugar de leitura - ou "tábua de trabalho" - que subverte alguns elementos fundamentais da episteme a partir da qual pensamos.

Trabalhos com esse viés, nas palavras de Andrade e colaboradores (2008): "[...] nos anunciam embaraçamentos entre categorias: o mundo dos seres fantásticos e dos seres verídicos dobrando-se e criando outras pregas de 
possibilidades para o existir, para o ver, para a ciência, para a arte [...]" (Ibidem, 2008 , s.p.). Desse modo, tais trabalhos confrontam nossos valores enraizados e nos incomodam diante de uma realidade especulada: e se a narrativa fosse outra? E se nossas categorias englobassem os seres fantásticos como parte do real?

Ao se utilizar de componentes retóricos tipicamente científicos, Corrêa desloca a narrativa ficcional, especulando sobre seu caráter de verdade. Nas palavras do artista, em entrevista citada por Gonçalves (2011):

Quando tiro esse animal da vida das pessoas, lá da dona Maria, da Amazônia, que viu uma sereia; quando tiro essa informação do cotidiano e a coloco num compêndio de ciências, estou dizendo à dona Maria que aquilo no qual ela acredita é verdade (IBIDEM, p. 17).

Para Gonçalves (idem), o apagamento ao qual essas histórias são submetidas remove-as do imaginário popular, e os sentidos simbólico e fabular são apagados com o objetivo de não perturbar o efeito de verdade que a ciência produz. "Contos, (en)cantos, magia, sedução, sexualidade, pontos que atravessam o mito da sereia, e não cabem ao discurso científico, são descartados para não ameaçarem os sentidos de verdade [...]" (Ibidem, p. 17-18). O caráter experimental da arte permite embaralhar de novo essas narrativas.

São as experimentações que para Foucault (2013) representam a beleza daquilo que ele chama de "heterotopias", uma vez que especulam possibilidades alternativas de espaço, observam lugares diferentes e celebram as complexidades. Dada a possibilidade de emaranhado, de mistura, as heterotopias, para o autor, "inquietam, sem dúvida porque solapam secretamente a linguagem, $[\ldots]$, porque fracionam os nomes comuns ou os emaranhados, porque arruínam de antemão a 'sintaxe'"' (FOUCAULT, 2007, p. XIII). Ondina, desse modo, configuraria uma "heterotopia das ilusões" (FOUCAULT, 2013, p. 120), representando um espaço de contestação do tópos de nosso pensamento, pautado nos parâmetros de verdade da ciência.

Para obter esse efeito de embaralhamento, Corrêa cria um universo plástico com visualidade inspirada naquela dos atlas de anatomia antigos, como o de Henry Gray, no século XIX, um marco na área (exemplo nas figuras 3 e 4). O conceito de modalidade, tal como definido por Theo Van Leeuwen (2005), pode nos ajudar a pensar sobre essa estratégia visual. Tal conceito indica os graus de verossimilhança (ou grau de modalidade) de enunciados como efeitos de pistas presentes nos próprios enunciados. Por exemplo, a exposição de um diagrama científico em um trabalho o faz, normalmente, 
Figuras 3 e 4

Ilustrações presentes no atlas de anatomia de Henry

Gray

Ilustrações de $\mathrm{H}$. V. Carter, títulos e técnica s.d, 1858 Fonte: Gray, Henry. Anatomy: Descriptive and Surgical, 1858 , p. 316 e 368 https://ia800500. us.archive.org/7/ items/anatomydescripti1858gray/ anatomydescripti1858gray.pdf
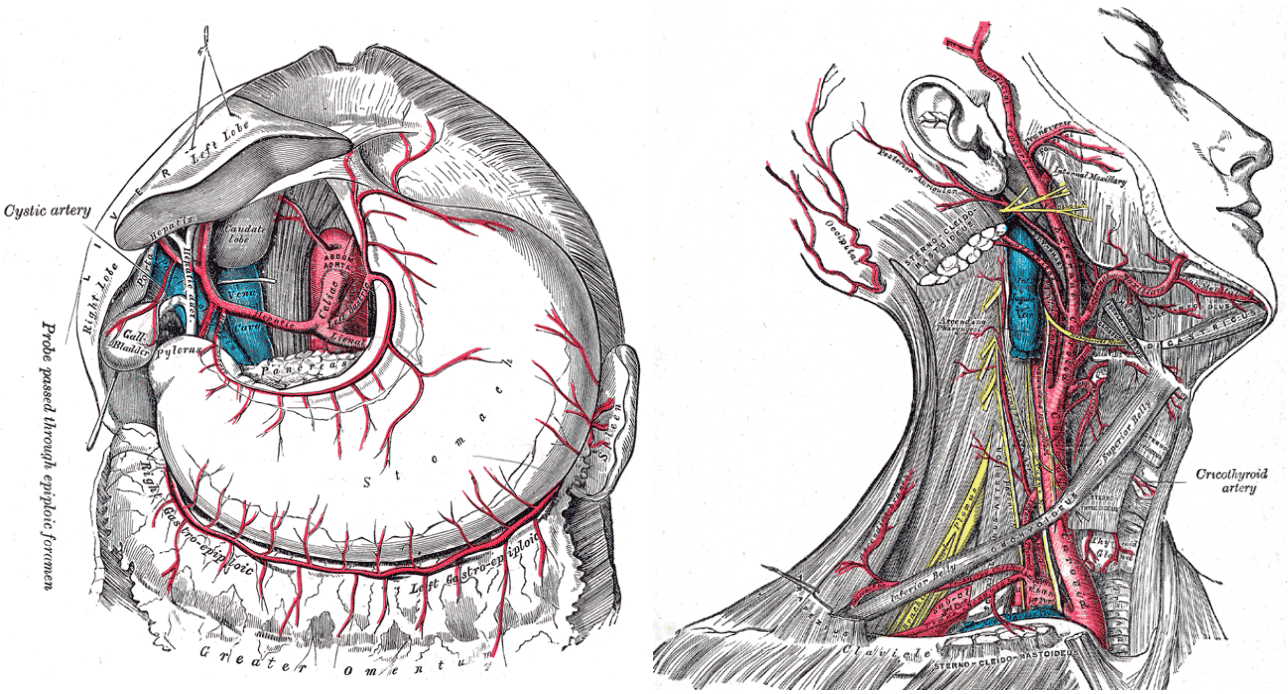

ser percebido com um alto valor de verdade e não como ficção ou fantasia. Sem a preocupação de ir a fundo nos parâmetros de análise referentes aos níveis de modalidade de uma imagem, o conceito se mostra interessante justamente por mostrar que a organização de componentes visuais típicos da ciência (gráficos, linhas, diagramas, imagens anatômicas, etc.) conferiria à obra certo caráter de verdade; colocado imediatamente em questão, porém, quando nos damos conta do objeto representado com esses recursos - seres míticos, cujo estatuto, na mesma episteme que empresta a tais recursos visuais sua alta modalidade, é o de "mera fantasia".

As estruturas anatômicas presentes em Ondina são bem construídas e estão apoiadas por blocos de textos que procuram reforçar a narrativa visual. A nota intitulada "Região Occipital do crânio" diz: "Pode-se perceber o cérebro deste 'animal' depois de removida parte da membrana exterior. O cérebro centraliza a atividade fisiológica e a interpretação dos impulsos externos. [...] O cérebro constitui juntamente com a medula espinhal o sistema nervoso central. Ambos os componentes se acham resguardados por estruturas ósseas. $O$ encéfalo consta de três partes diferenciadas: a porção posterior, a média e a anterior [...]". A linguagem desses fragmentos textuais se une, então, à visualidade de Atlas de anatomia para reforçar o caráter "científico" do todo.

Ondina, enfim, desliza as representações da ciência e nos apresenta a possibilidade de experimentação narrativa. Trata-se, portanto, de um exercício que explora, dentro de uma perspectiva arqueológica, alternativas classificatórias de cenários (fictícios), articulados a partir da linguagem científica. Apresentar caminhos que demonstram o potencial exploratório do campo da arte pela utilização de narrativas visuais de alto grau de ver- 
Figura 5

Walmor Corrêa

Unheimlich, Ima-

ginário Popular

Brasileiro, 2005

Trecho intitulado

"Região Occipital do

Crânio" à direita da

ilustração

Acrílica e grafite

sobre tela, $195 \mathrm{x}$

$130 \mathrm{~cm}$

Fonte: http://www.

walmorcorrea.com.

$\mathrm{br} /$ obra/unheimli-

ch-imaginario-po-

pular-brasileiro dade pode ser uma forma de potencializar outras narrativas, que não cabem ou que foram historicamente excluídas por um conjunto de práticas que corroboram para a perpetuação dos saberes canônicos.

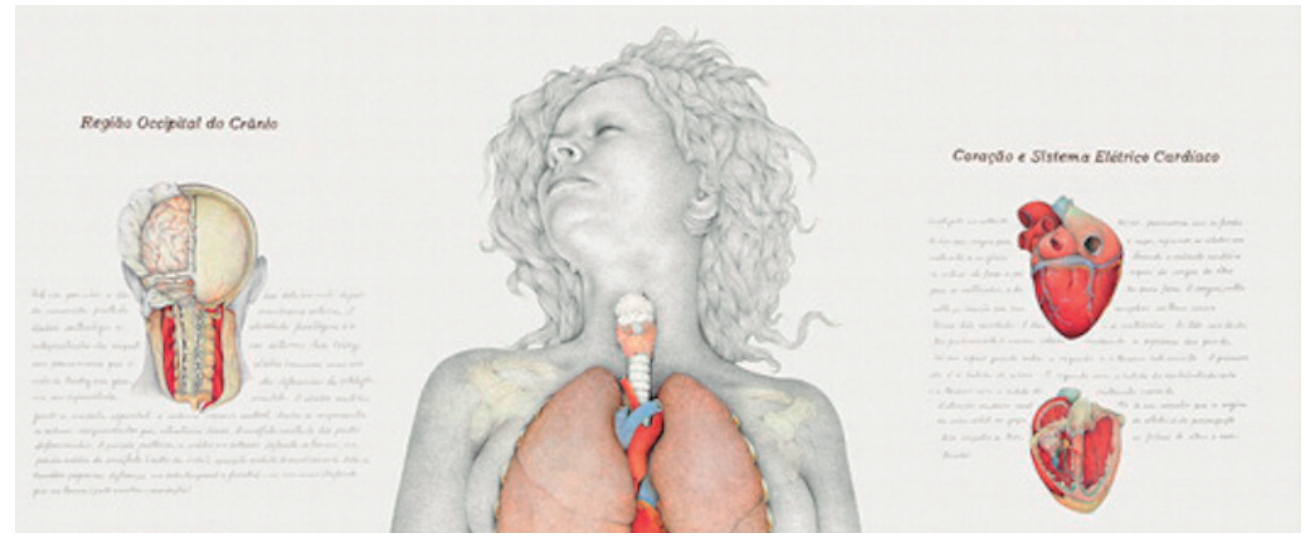

\section{Considerações finais}

Este trabalho apresentou, inicialmente, uma reflexão sobre a virada epistêmica que instituiu uma visão científica de mundo - a qual embora, em muitos aspectos, diferente de nossa atual visão de mundo, permite vislumbrar como o valor científico de verdade encobre certas formas de pensar e de relação com a natureza antes comuns. Em seguida, partimos para uma análise da obra Ondina, parte da série Unheimlich, imaginário popular brasileiro (2005), do artista visual Walmor Corrêa, com o intuito de mostrar como a experimentação artística pode nos colocar em contato com maneiras de pensar a princípio estranhas para nós - isto é, encobertas pela episteme que é a nossa. Ondina mostra-se como um exercício desestabilizador, uma vez que dribla o discurso legitimado pela ciência. Esse trabalho abre, portanto, espaço para o entendimento de que novas fabulações potencializadoras podem ser estimuladas a fim de incentivar o debate acerca dos valores vigentes (e excludentes) presentes na episteme atual. A arte, enfim, como um lugar de debate e de experimentação.

\section{REFERÊNCIAS}

AGAMBEN, Giorgio. Ninfas. Valencia: Pré-textos, 2010.

ANCHIETA, Padre José de. Carta de São Vicente [Caderno n. 7 da série Documentos históricos]. São Paulo: Conselho Nacional da Reserva da Biosfera da Mata Atlântica, 1997. Disponível em: <http://www.rbma.org.br/ rbma/pdf/Caderno_07.pdf>. Acesso em 20 jun. 2020. 
ANDRADE, E. C. P; SPEGLICH, E.; ROMAGUEIRA, A. Dispersões, distensões e $(m)$ emoções: arte, ciência, ser-á? ComCiência, n. 10, 2008. Disponível em: <http://comciencia.scielo.br/scielo.php?script=sci_arttext\&pi$\mathrm{d}=\mathrm{S} 1519-76542008000300016 \&$ lng=e\&nrm=iso >. Acesso em 20 jun. 2020.

ARTIFON, Sara. Ondina e as formas em metamorfose: uma poética inquietante. Dissertação de Mestrado em Artes do Programa de Pós-graduação em Arte do Instituto de Artes da Universidade de Brasília. Brasília, 2016.

BACON, Francis. Novum Organum. São Paulo: Nova Cultural, 1997.

BARTRA, Roger. Wild men in the looking glass: the mythic origins of European otherness. University of Michigan Press, 1994.

BERGER, John. Modos de ver. São Paulo: Rocco, 1999.

CARVALHO, Carla Gavilan. Nem perfeita, nem recusável: simplesmente faIha. A ciência a partir dos questionamentos da arte. IARA: Revista de Moda, Cultura e Arte. São Paulo, v. 3, n. 1, 2010.

CHIARELLI, Tadeu. Aproximações. In: Walmor Corrêa [website], 2002. Disponível em: <http://http://www.walmorcorrea.com.br/texto/apropriacoes>. Acesso em 20 jun. 2020.

FOUCAULT, Michel. As palavras e as coisas: uma arqueologia das ciências humanas. São Paulo: Martins Fontes, 2007.

De outros espaços. Estudos Avançados, São Paulo, v. 27, n. 79, 2013.

GONÇALVES, Maria Lívia Conceição Marques Ramos. A instalação Memento Mori, de Walmor Corrêa, como artefato de divulgação científica. Dissertação de Mestrado em Divulgação Científica e Cultural do Instituto de Estudos da Linguagem da Universidade Estadual de Campinas. Campinas, 2011.

GRAY, Henry. Anatomy: Descriptive and Surgical. London: John W. Parker and Son, 1858.

JUNG, Carl Gustav. O Espírito na arte e na ciênica. São Paulo: Editora Vozes, 2011.

LEEUWEN, Theo Van. Introducing social semiotics. London; New York: Routledge, 2005. 
PARACELSO. Opera Omina - A chave da alquimia. São Paulo: Três, 1973.

A Book on Nymphs, Sylphs, Pygmies and Salamanders, and on the Other Spirits. In: . Four Treatises of Theophrastus Von Hohenheim Called Paracelsus. Trans. C. L. Temkin et al. Baltimore: The John Hopkins University Press, 1996.

PARÉ, Ambroise. On Monsters and Marvels. University of Chicago Press, 1982.

SANTOS, Luís Henrique. Biologia tem uma história que não é natural. In: COSTA, M. V (org.). Estudos Culturais em Educação: mídia, arquitetura, brinquedo, biologia, literatura, cinema... Porto Alegre: Editora da UFRS, 2000.

TALAMONI, ACB. Anatomia, ensino e entretenimento. In: Os nervos e os ossos do ofício: uma análise da aula de Anatomia. São Paulo: UNESP, 2014.

THOMAS, Keith. O homem e o mundo natural: mudanças de atitude em relação às plantas e aos animais (1500-1800). São Paulo: Companhia das Letras, 2010. 